Stephany Fulda Magdolna Hornyak Karin Müller Lukas Cerny Pierre A. Beitinger Thomas C. Wetter

\section{Development and validation of the Munich Parasomnia Screening (MUPS)}

\author{
A questionnaire for parasomnias and nocturnal behaviors
}

\section{Entwicklung und Validierung des Münchner Parasomnie-Screening (MUPS): Ein Fragebogen zur Erfassung von Parasomnien und nächtlichen Verhaltensweisen}

Zusammenfassung Ziel dieser Studie war die Entwicklung und Validierung eines Screeninginstrumentes zur Erfassung der Lebenszeitprävalenz und Häufigkeit von Parasomnien und nächtlichen Verhaltensweisen (Münchner Parasomnie-Screening - MUPS). Bei diesem Fragebogen handelt es sich um ein Selbstbeurteilungsinventar für Erwachsene, das 21 Merkmale umfasst. Die Entwicklung des MUPS wurde an Patienten mit psychiatrischen Störungen (Gesamtanzahl: $\mathrm{n}=74$ ) durchgeführt. Die Validierung erfolgte bei drei Gruppen: Patienten mit psychiatrischen Störungen $(n=65)$, Pati-

Received: 22 November 2007

Accepted: 14 February 2008

S. Fulda, MSc $(\bullet) \cdot$ K. Müller $\cdot$ L. Cerny

P. A. Beitinger - T. C. Wetter

Max Planck Institute of Psychiatry

Kraepelinstraße 2-10

80804 Munich, Germany

Tel.: +49-89/30622-226

Fax: +49-89/30622-605

E-Mail: fulda@mpipsykl.mpg.de

M. Hornyak

Dept. of Psychiatry and Psychotherapy

University Medical Center

Freiburg, Germany enten mit Schlafstörungen $(n=50)$ sowie gesunden Personen $(n=65)$. In einer zufällig ausgewählten Stichprobe von $20 \%$ aller Befragten wurde der MUPS mit den Ergebnissen eines ausführlichen klinischen Interviews, das von einem schlafmedizinischen Experten durchgeführt wurde, verglichen. Die Validität wurde für jede der 21 erfassten nächtlichen Verhaltensweisen hinsichtlich der Lebenszeitprävalenz bestimmt. Die Sensitivität war bei 19 von 21 Merkmalen größer oder gleich $90 \%$, die Spezifität war für alle Items größer als $80 \%$ bzw. für 19 von 21 Items größer als $90 \%$. Von noch größerer Bedeutung im Hinblick auf die Verwendung des MUPS in der schlafmedizinischen Praxis ist es, dass der positive und negative prädiktive Wert für die Mehrzahl der Items hoch war. Zusammenfassend ist der MUPS ein valides und einfach anwendbares Screeninginstrument zur Erfassung von Parasomnien und nächtlichen

Verhaltensweisen.

Schlüsselwörter Parasomnie Fragebogen - Validierung - MUPS - schlafbezogene Bewegungsstörungen - nächtliche Verhaltensweisen

Summary We have developed and validated the Munich Parasomnia Screening (MUPS) ques- tionnaire, a self-rating instrument with 21 items assessing the lifetime prevalence and current frequency of parasomnias and nocturnal behaviors in adult persons. The MUPS was developed with psychiatric patients (total $n=74$ ). For the validation study the MUPS was given to three large groups, i.e. psychiatric patients $(n=65)$, sleep-disordered patients $(n=50)$, and healthy controls $(n=65)$. In a randomly chosen subset of $20 \%$ of these subjects the MUPS was compared to the information obtained in a detailed clinical interview with a sleep medicine expert. Validity was assessed for lifetime prevalence of any frequency for each of the 21 nocturnal behaviors. For the individual items of the MUPS sensitivity was equal to or above $90 \%$ for all but two of 21 items and specificity was above $80 \%$ for all items and above $90 \%$ for 19 of 21 items. More importantly, concerning the use of the MUPS in clinical practice, positive and negative predictive values of the single items were high for the majority of items. The MUPS appears to be an easy to use and valid instrument in the recognition of nocturnal behaviors and parasomnias.

Key words parasomnia questionnaire - validation - MUPS - sleep-related movements nocturnal behavior 


\section{Introduction}

Parasomnias are undesirable phenomena occurring during sleep and involving skeletal muscle activity [1]. Diagnosis is made on the basis of findings from the clinical interview and video polysomnography [22]. The knowledge of and scientific interest in parasomnias have been growing in recent years. Studies suggest that parasomnias occur more frequently than previously assumed [14]. The identification of parasomnias has clinical relevance as these disorders may lead to serious consequences such as sleep-related injuries and psychological distress due to the repeated awakenings [8]. Furthermore, parasomnias can be easily overlooked or misdiagnosed. In addition, there are several normal variants or behaviors of unclear clinical significance such as hypnic jerks or sleep talking that can be experienced throughout the night [1].

Except when the sleep-related behavior is the chief complaint of the patient, in clinical practice it is often not possible, due to time constraints, to explicitly inquire about each of the known sleep-related behaviors includ- ing relatively rare disorders such as the exploding head syndrome or nocturnal groaning. Clinical practice necessitates many clinicians to restrict a sleep history to the most likely (prevalent) sleep-related behavior; therefore, a screening questionnaire would be helpful in detecting unusual nocturnal motor phenomena. We sought to develop a simple questionnaire to assess the lifetime occurrence and current frequency of a large range of sleep-related behaviors.

A literature search revealed a general paucity of validated instruments for the assessment of parasomnias and nocturnal behaviors. In Table 1 we have listed those instruments for which information on validity was available. A limited number of parasomnias or sleep-related movement disorders are assessed within general sleep questionnaires such as the SLEEP-50 [20], which validated questions on nightmares and sleep walking, the Global Sleep Assessment Questionnaire [18] (periodic leg movements (PLM), unspecified parasomnias), the Sleep Disorder Questionnaire [4] (periodic leg movement disorder (PLMD)), and the Sleep-Eval System [15] which has been validated with respect to REM sleep be-

Table 1 Validated questionnaires for parasomnias in adults

\begin{tabular}{|c|c|c|c|}
\hline Instrument & Diagnosis/Description & Subjects & Validity \\
\hline RBDSQ [21] & $\begin{array}{l}\text { RBD } \\
10 \text { items }\end{array}$ & $\begin{array}{l}54 \text { RBD patients, } 133 \text { normal } \\
\text { subjects, } 160 \text { sleep-disordered patients }\end{array}$ & SE 0.96; SP 0.56 \\
\hline Sleep-Eval System [15] & $\begin{array}{l}\text { ICSD disorders } \\
\text { computerized tool }\end{array}$ & 105 sleep-disordered patients & $\begin{array}{l}\text { RBD: agreement with clinical diagnosis } 100 \% \\
\text { ( } 2 \text { cases) }\end{array}$ \\
\hline SLEEP-50 [20] & $\begin{array}{l}\text { DSM-IVR sleep disorders } \\
50 \text { item questionnaire }\end{array}$ & $\begin{array}{l}377 \text { college students, } \\
246 \text { sleep-disordered patients, } \\
32 \text { nightmare sufferers }\end{array}$ & $\begin{array}{l}\text { Sleepwalking ( } 4 \text { cases) } \\
\text { SE } 1.0 ; \text { SP } 1.0 \\
\text { Nightmares ( } 32 \text { cases) } \\
\text { SE } 0.84 ; \text { SP } 0.77\end{array}$ \\
\hline GSAQ [18] & $\begin{array}{l}7 \text { sleep disorders } \\
\text { including PLM, } \\
\text { parasomnias } \\
11 \text { or } 19 \text { items }\end{array}$ & 212 sleep-disordered patients & $\begin{array}{l}\text { PLM (7 cases), } \\
\text { cut-off 20: SE } 0.93 ; \text { SP } 0.52 \\
\text { cut-off 47: SE } 0.43 ; \text { SP } 0.93 \\
\text { Parasomnias ( } 4 \text { cases), } \\
\text { cut-off 45: } \\
\text { SE } 1.0 ; \text { SP } 0.49 \\
\text { cut-off } 65 \text { : SE } 0.33 ; \text { SP } 0.98\end{array}$ \\
\hline $\begin{array}{l}\text { Inventory of } \\
\text { Nocturnal Eating [24] }\end{array}$ & $\begin{array}{l}\text { Sleep-related eating disorder } \\
7 \text { sections with unknown } \\
\text { number of questions }\end{array}$ & $\begin{array}{l}23 \text { patients with sleep-related } \\
\text { eating disorder }\end{array}$ & SE 0.91 \\
\hline $\begin{array}{l}\text { NESQ abbreviated } \\
\text { version [23] }\end{array}$ & $\begin{array}{l}\text { NES } \\
9 \text { items }\end{array}$ & 59 overweight night snackers & $\begin{array}{l}\text { vS. structured diagnostic interview* } \\
\text { SE "poor"*** } \\
\text { SP "poor"*** }\end{array}$ \\
\hline $\begin{array}{l}\text { Night Eating } \\
\text { Syndrome screening } \\
\text { question [23] }\end{array}$ & $\begin{array}{l}\text { NES } \\
1 \text { item }\end{array}$ & 59 overweight night snackers & $\begin{array}{l}\text { vs. structured diagnostic interview* } \\
\text { SE } 0.80-0.98 \\
\text { SP } 0.11-0.67\end{array}$ \\
\hline SDQ [4] & $\begin{array}{l}4 \text { sleep disorders } \\
\text { including PLMD } \\
175 \text { item questionnaire }\end{array}$ & $\begin{array}{l}39 \text { normal controls, } 141 \text { sleep apnea patients, } \\
39 \text { narcolepsy patients, } 47 \text { patients with } \\
\text { psychiatric sleep disorders, } 66 \text { PLMD patients }\end{array}$ & $\begin{array}{l}\text { PLMD } \\
\text { Males: SE } 0.67 ; \text { SP } 0.46 \\
\text { Females: SE } 0.65 ; \text { SP } 0.49\end{array}$ \\
\hline
\end{tabular}

SE sensitivity; SP specificity; NES Night eating syndrome; PLMD Periodic limb movement disorder; RBD REM sleep behavior disorder; GSAQ Global Sleep Assessment Questionnaire; NESQ Night Eating Syndrome Questionnaire; RBDSQ REM sleep behavior disorder screening questionnaire; SDQ Sleep Disorders Questionnaire

* Diagnosis was assessed referring to six different definitions derived from the literature with similar but not identical wording

** "Choice of a single cut point resulted in both poor sensitivity and specificity because of a large number of misclassifications" ([23], p. 69) 
havior disorder (RBD). In addition, two questionnaires $[23,24]$ and one screening question [23] for nocturnal eating have been validated in groups of subjects with night eating. Recently, the REM sleep behavior disorder screening questionnaire (RBDSQ) has been developed and validated in three large groups of subjects ([21], see Table 1). With the exception of the RBDSQ none of the other instruments are available in German and none covers all parasomnias and sleep-related movement disorders listed in the International Classification of Sleep Disorders (ICSD-2, [1]). We developed a 21-item screening questionnaire, the Munich Parasomnia Screening (MUPS), which assesses the lifetime prevalence and current frequency of parasomnias and unusual nocturnal behaviors in adults.

\section{Development of the Munich Parasomnia Screening (MUPS)}

The development of the MUPS consisted of (i) collecting questionnaire items, (ii) generating a response format, and (iii) creating an iterative process of evaluating and refining the questionnaire with a total of four samples of psychiatric patients (see overview in Fig.1). Psychiatric patients were chosen for reasons of convenience but also because an increased prevalence of parasomnias can be expected in this sample.

For item generation we considered all sleep-related behaviors listed in the ICSD-2 under the heading of parasomnias, sleep-related movement disorders or normal variants. The very first questionnaire version assessed 19 different sleep-related behaviors by using 19 questions. In the following, however, we added two questions to increase clarity. First, apart from asking for sleep-related eating (no or partial consciousness) we added a new item assessing nocturnal eating (full consciousness) because it was our impression that these were confused by the subjects. Second, in addition to the two separate questions regarding sleep walking and possible REM-sleep-behavior disorder (RBD) we added a new question specifically asking for violent behavior during sleep such as kicking or hitting somebody to increase precision in assessing possible $\mathrm{RBD}$.

Several different response formats were tried with the aim to assess both the lifetime history and the current frequency of the nocturnal behaviors. The final frequency response format includes seven categories two of which assess lifetime prevalence ("never" and "previously, _ years ago but not now"); five assess current frequency (see response format in Fig.2). In addition, in one item the subject has to state whether the nocturnal behavior in question had been observed by other persons and/or by themselves; finally, for each question a field for additional comments was included.

Questionnaire development started with a first pre- liminary version and proceeded with an iterative process of presenting the questionnaire to groups of patients, evaluating the outcome and subsequently adapting and refining the questionnaire (Fig. 1). A total of four groups of psychiatric patients participated in the development process. In the very first group of patients the questionnaire was actually completed with the help of the experimenter and the subjects were explicitly asked whether they understood and how they interpreted the questions. Because the final use of the questionnaire was to hand it over to diverse groups of subjects, the questionnaire was completed by the subjects without any help, starting from the second group (version 2). Evaluation also included completeness of the questionnaire. During the questionnaire development the wording of both the items and the response formats were changed iteratively. At one point an example was added, which was subsequently removed because it confused the subjects. While the first two versions optimized comprehensibility of the questionnaire, the next two sought to maximize validity of the questions. Therefore, a detailed sleep history was obtained by a sleep expert in several of the subjects. Overall, the development was based on evaluating the questionnaire in a total of 74 psychiatric patients (Fig. 1). In general, it took subjects 10 to $20 \mathrm{~min}$ utes to complete the questionnaire.

\section{Description of the MUPS}

The MUPS is a self-rating questionnaire that assesses 21 different nocturnal behaviors and can be downloaded from the homepage of the German sleep society DGSM (Deutsche Gesellschaft für Schlafforschung und Schlafmedizin) in an English and German version (see Appendix). The 21 nocturnal behaviors (see Fig.2) are assessed using 21 different questions; in addition, one other item inquires about other nocturnal behaviors to be answered in an open format. The lifetime history or frequency of each behavior is assessed using the same response format and the following seven categories. The overall question was "Have you ever noticed the following behavior?" and the response categories were (1) no, never, (2) previously, __ years ago, but not now, (3) very rarely - less than once a year, (4) rarely - one or more times per year, (5) sometimes - one or more times per month, (6) frequently - one or more times per week, and (7) very frequently - every or nearly every night. In addition, for each item it was asked "How do you know that the behavior occurred?" and the subjects could indicate with a tick mark the categories "observed by myself" and/or "observed by others". The only exception was the item inquiring for periodic leg movements during sleep. Here it was stressed in the question that this behavior could only be observed by another person and consequently only the respective response category was available. Fi- 
Development of the MUPS

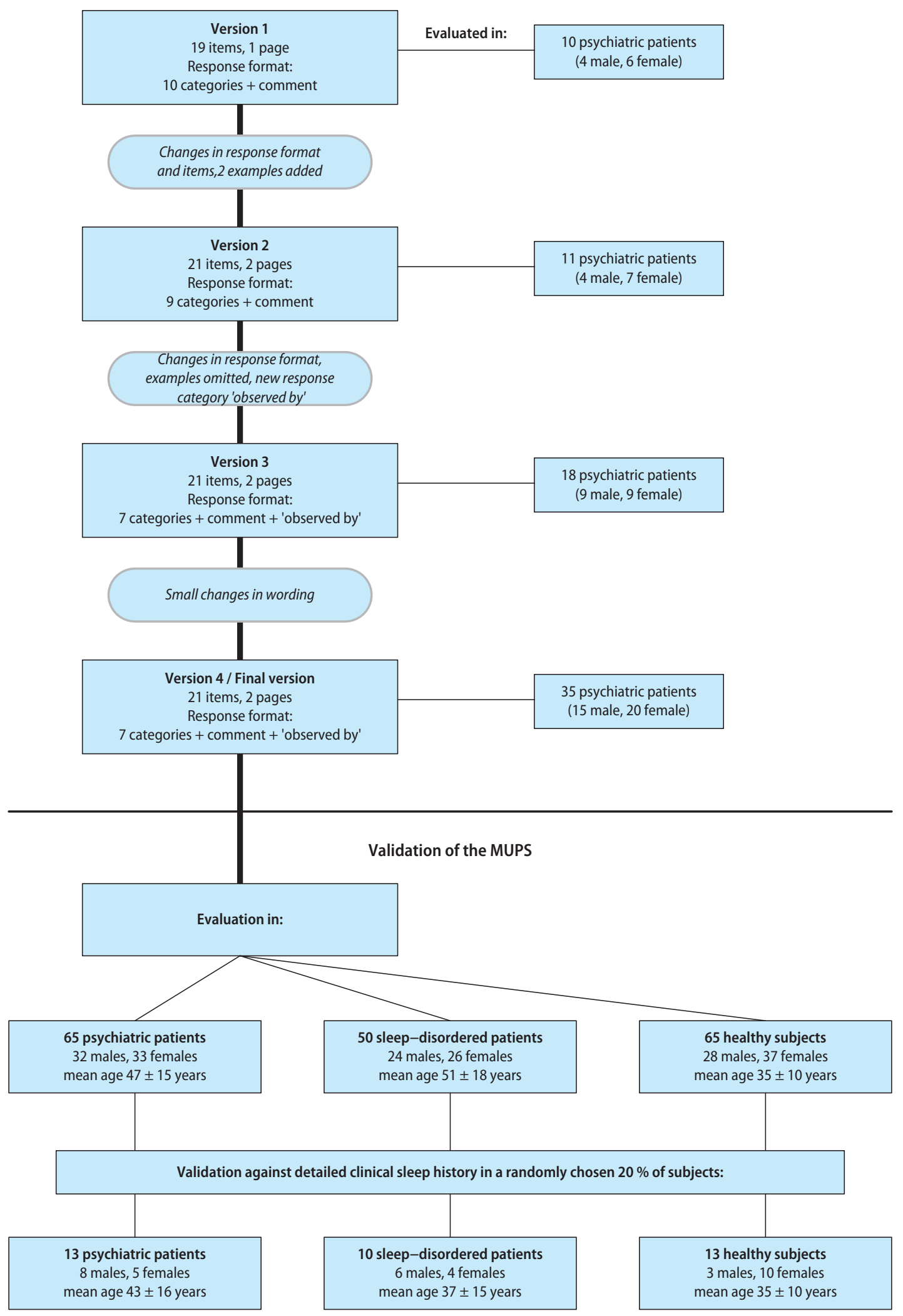

Fig. 1 Overview about samples and procedures in the development and validation of the MUPS 


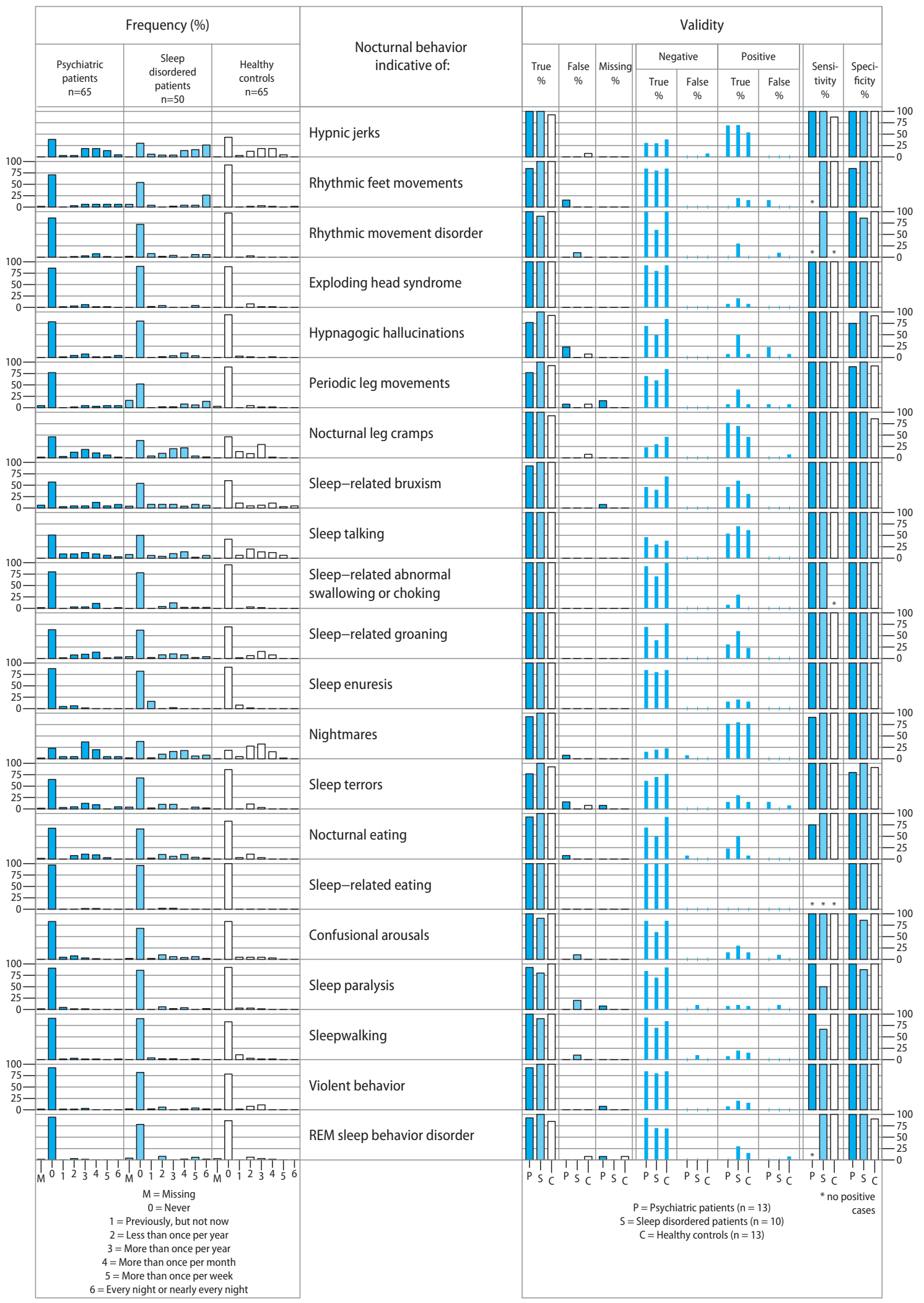

Fig. 2 Left panels Frequency of parasomnias and nocturnal behaviors assessed with the MUPS in psychiatric patients $(n=65)$, sleep-disordered patients $(n=50)$ and healthy controls $(n=65)$. Right panels Agreement between a detailed clinical interview with a sleep expert and MUPS questionnaire responses. Correspondence for lifetime history was coded as true negative, true positive, false negative, and false positive. The derived values for sensitivity and specificity are shown in the very right columns 
nally, for each item there was some space where subjects were asked to provide comments if they felt that these were required.

The two-page questionnaire assessed 21 different nocturnal behaviors. Across the questionnaire these were approximately ordered by their time of occurrence during the night. Therefore, the first five items explored (1) hypnic jerks, (2) rhythmic foot tremor, (3) rhythmic movement disorders, (4) exploding head syndrome, and (5) hypnagogic hallucinations. The next seven items explored simple behaviors, some of them stereotyped. The items explored (6) periodic leg movements during sleep, (7) nocturnal leg cramps, (8) sleep related bruxism, (9) sleep talking, (10) sleep-related abnormal swallowing or choking, (11) sleep-related groaning, and (12) sleep enuresis. For the item on periodic leg movements only the category "observed by others" was available and it was stressed in the question that because this behavior occurred during sleep, it could not be observed by the person him- or herself. On the second page we explored (13) nightmares, (14) sleep terrors, (15) nocturnal eating (full consciousness), (16) sleep-related eating (partial or no consciousness), (17) confusional arousals, and (18) sleep paralysis. The last three questions dealt with (19) sleep walking, (20) violent behavior during sleep, and (21) RBD. We decided to specifically ask for violent behavior during sleep because we wanted to define RBD more precisely. More importantly, however, we wanted to make sure that we would obtain information about violent behaviors during sleep even if the subject was not aware that he was dreaming or did not think that this was related to sleep walking. Finally, one additional item inquired whether there was any other unusual behavior occurring during the night and asked subjects to describe it in the space provided.

The questionnaire was accompanied by a sheet providing information and a detailed instruction. In the information of the research version it was stated that the questionnaire was developed to assess the frequency of various sleep-related behaviors, that the completion of the questionnaire was voluntary, and that the data assessed by the questionnaire would be processed in an anonymous form. The instruction asked the subject to remember to answer the question "How do you know that the behavior occurred?". It drew attention to the space provided for comments and included, as an example, the case in which the frequency judging was difficult because the behavior occurred at very irregular intervals or the subject knew or suspected a definite cause for the observed behavior such as lack of magnesium in the case of sleep-related leg cramps. Finally, it explained that if the behavior had occurred at a previous time but not currently this should be documented in the respective response category.

\section{Validation of the MUPS}

\section{Subjects}

The final version of the questionnaire was given to three groups of subjects: 65 psychiatric inpatients (32 male, 33 female, mean age $47 \pm 15$ years), 50 sleep-disordered patients referred to the sleep lab (24 male, 26 female, mean age $51 \pm 18$ years), and 65 normal subjects ( 28 male, 37 female, mean age $35 \pm 10$ years) recruited among hospital staff, students, friends and acquaintances of the authors. None of the subjects were paid for their participation and all gave written informed consent.

\section{Procedure}

In each group, a random $20 \%$ of subjects was selected for the validation. The validation sample included 13 psychiatric patients ( 8 male, 5 female, mean age $43 \pm 16$ years), 10 sleep-disordered patients ( 6 male, 4 female, $37 \pm 15$ years), and 13 healthy subjects ( 3 males, $10 \mathrm{fe}-$ males, $35 \pm 10$ years). Randomization was achieved by placing a note in every fifth questionnaire; questionnaires were handed out by a person blind as to where the note was placed. The note asked the subject to make an appointment for an interview. The interview consisted of a general and specific sleep history taken by one of three clinical sleep experts (SF, TCW, PB). In addition, after a detailed sleep history was taken, the parasomnia questionnaire was discussed and each individual item of the parasomnia questionnaire was explained to the subject to make sure that the subject had correctly understood the meaning of the particular item.

For the validation study, we coded for each questionnaire the number of missing questions and for each question whether the presence or absence of the sleeprelated behavior was correctly identified by the subject as compared to the information yielded in the clinical sleep interview. For each item the response was classified as missing, true positive, true negative, false positive, and false negative. Sensitivity was computed as the number of true positives divided by the sum of true positives and false negatives. Likewise, specificity was computed by dividing the number of true negatives by the sum of true negatives and false positives. The positive predictive value refers to the probability that a positive test result will be true and is computed as the sum of true positives divided by the sum of all positives. Similarly, the negative predictive value describes the probability that a negative test result will be true (sum of true negatives / sum of all negatives)[13]. 


\section{Results}

Fig. 2 provides a summary concerning the prevalence of nocturnal behaviors in the three samples and the results of the validation procedure. Overall, completeness of the questionnaires was excellent. In the complete sample of 180 subjects there were no missing data for six items, for another six items there was a single missing data value $(0.6 \%)$, two items each had two (1.1\%), three (1.7\%), or four $(2.2 \%)$ missing data values. Finally, for another three items there were five $(2.8 \%$, REM sleep behavior disorder), six (sleep-related bruxism, 3.3\%), and 13 (7.2\%, periodic leg movements) missing values. Lifetime prevalence (any frequency) is also given in Table 2. The most frequently experienced or reported events in all samples were nightmares, hypnic jerks, nocturnal leg cramps, sleep-related bruxism, and sleep talking. Behaviors indicative for sleep-related eating were only rarely reported in our sample while nocturnal snacking was decidedly more frequent. The right-hand side of Fig. 2 and Table 3 provides details about the validation of the questionnaire. Overall, both sensitivity and specificity were found to be satisfactory ( $>75 \%$, Table 3$)$. With rare exceptions, the answers in the questionnaire reflected those assessed in a detailed clinical interview. Sensitivity describes the ability of the questionnaire to correctly identify those patients with a given behavior. From 532 single negative answers that were evaluated only 5 $(0.9 \%)$ turned out to be false negative. In one case hypnic jerks, nightmares, nocturnal eating, sleep paralysis or sleep walking were not reported in the questionnaire. In two cases (sleep paralysis, sleep walking) the behavior in question had occurred only one or two times more than 10 or more years ago. In the other two cases, the behavior occurred very infrequently (less than once a year; nightmares, nocturnal eating). In one case (hypnic jerks), the subject simply made a mistake. For one item - sleep-related eating - no sensitivity could be computed because no subject reported this behavior. Within the group of psychiatric patients, none of the patients reported rhythmic feet movements, rhythmic movement disorder, or behavior indicative of REM sleep behavior disorder. In healthy controls, none reported rhythmic movement disorder.

Specificity describes how well the absence of behaviors is assessed by the questionnaire. Out of 216 positive answers, 17 (7.9\%; from 13 subjects) were false positive as determined in the clinical interview. These concerned the items rhythmic feet movements $(n=1$ psychiatric patient), rhythmic movement disorder $(\mathrm{n}=1$ sleep-disordered patient), periodic leg movements ( $\mathrm{n}=2$ patients), nocturnal leg cramps $(n=1$ healthy control),
Table 2 Lifetime prevalence (any severity) of nocturnal behaviors in psychiatric patients, sleep-disordered patients, and controls and in a randomly chosen $20 \%$ of subjects (validation sample)

\begin{tabular}{|c|c|c|c|c|}
\hline \multirow[b]{2}{*}{$\begin{array}{l}\text { Nocturnal behavior } \\
\text { indicative of: }\end{array}$} & \multicolumn{4}{|c|}{ Lifetime prevalence } \\
\hline & $\begin{array}{l}\text { Psychiatric } \\
\text { patients } \\
(n=65) \\
\%\end{array}$ & $\begin{array}{l}\text { Sleep-disordered } \\
\text { patients } \\
(n=50) \\
\%\end{array}$ & $\begin{array}{l}\text { Healthy } \\
\text { controls } \\
(n=65) \\
\%\end{array}$ & $\begin{array}{l}\text { Validation } \\
\text { sample } \\
(n=36) \\
\%\end{array}$ \\
\hline Hypnic jerks & 61.5 & 70.0 & 56.9 & 63.9 \\
\hline Rhythmic feet movements & 29.2 & 46.0 & 7.7 & 16.7 \\
\hline Rhythmic movement disorder & 13.8 & 28.0 & 3.1 & 11.1 \\
\hline Exploding head syndrome & 13.8 & 10.0 & 10.8 & 11.1 \\
\hline Hypnagogic hallucinations & 21.5 & 20.0 & 6.2 & 30.6 \\
\hline Periodic leg movements & 23.1 & 48.0 & 10.8 & 27.8 \\
\hline Nocturnal leg cramps & 53.8 & 62.0 & 53.8 & 66.7 \\
\hline Sleep-related bruxism & 43.1 & 46.0 & 40.0 & 47.2 \\
\hline Sleep talking & 49.2 & 50.0 & 58.5 & 61.1 \\
\hline Sleep-related abnormal swallowing & 20.0 & 22.0 & 4.6 & 11.1 \\
\hline Sleep-related groaning & 36.9 & 38.0 & 30.8 & 36.1 \\
\hline Sleep enuresis & 12.3 & 18.0 & 9.2 & 16.7 \\
\hline Nightmares & 76.9 & 62.0 & 81.5 & 77.8 \\
\hline Sleep terrors & 35.4 & 32.0 & 13.8 & 30.6 \\
\hline Nocturnal eating & 32.3 & 34.0 & 16.9 & 25.0 \\
\hline Sleep-related eating & 3.1 & 4.0 & 0 & 0 \\
\hline Confusional arousals & 16.9 & 32.0 & 16.9 & 22.2 \\
\hline Sleep paralysis & 9.2 & 14.0 & 7.7 & 13.9 \\
\hline Sleepwalking & 9.2 & 10.0 & 16.9 & 13.9 \\
\hline Violent behavior & 7.7 & 18.0 & 21.5 & 16.7 \\
\hline REM sleep behavior disorder & 6.1 & 22.0 & 13.8 & 22.2 \\
\hline
\end{tabular}


Table 3 Results of the validation: Sensitivity, specificity, positive and negative predictive values for the single items of the MUPS

\begin{tabular}{lrrrr} 
Nocturnal behavior indicative of: & SE & SP & PPV & NPV \\
\hline Hypnic jerks & 96 & 100 & 100 & 92 \\
Rhythmic feet movements & 100 & 94 & 67 & 100 \\
Rhythmic movement disorder & 100 & 97 & 75 & 100 \\
Exploding head syndrome & 100 & 100 & 100 & 100 \\
Hypnagogic hallucinations & 100 & 86 & 64 & 100 \\
Periodic leg movements & 100 & 93 & 75 & 100 \\
Nocturnal leg cramps & 100 & 93 & 96 & 100 \\
Sleep-related bruxism & 100 & 100 & 100 & 100 \\
Sleep talking & 100 & 100 & 100 & 100 \\
Sleep-related abnormal swallowing & 100 & 100 & 100 & 100 \\
Sleep-related groaning & 100 & 100 & 100 & 100 \\
Sleep enuresis & 100 & 100 & 100 & 100 \\
Nightmares & 97 & 100 & 100 & 87 \\
Sleep terrors & 100 & 89 & 70 & 100 \\
Nocturnal eating & 90 & 100 & 100 & 96 \\
Sleep-related eating & $*$ & 100 & 100 & 100 \\
Confusional arousals & 100 & 97 & 87 & 100 \\
Sleep paralysis & 75 & 97 & 75 & 97 \\
Sleepwalking & 83 & 100 & 100 & 97 \\
Violent behavior & 100 & 100 & 100 & 100 \\
REM sleep behavior disorder & 100 & 97 & 83 & 100 \\
\hline & & & &
\end{tabular}

SE Sensitivity, SP Specificity, PPV Positive Predictive Value, NPV Negative Predictive Value. ${ }^{*}$ No true positive cases

sleep terrors ( $n=2$ patients), confusional arousals $(n=1$ sleep-disordered patient), and sleep walking ( $\mathrm{n}=1$ sleepdisordered patient). In addition, four subjects erroneously reported hypnagogic hallucinations with three of them being psychiatric patients with psychotic symptoms.

\section{Discussion}

We have evaluated nocturnal events and behaviors with the MUPS in a large sample of psychiatric patients, sleepdisordered patients and healthy controls. The prevalence estimates for the different sleep-related behaviors in the complete group were in general accordance with what is known about the prevalence of parasomnias in the adult population [11]. Also in accordance with the literature, nightmares [17], nocturnal leg cramps [2,9], and sleeprelated bruxism $[12,16]$ were among the most frequently reported events. In a randomly chosen subset of $20 \%$ of the subjects validity with regard to a detailed clinical interview conducted by a sleep specialist was evaluated. Overall, the individual items of the MUPS showed substantial to perfect sensitivity and specificity. Sensitivity was equal to or above $90 \%$ for all but two of 21 items (sleep paralysis and sleep walking) with sensitivities of
$75 \%$ and $83 \%$, which can still be considered adequate. Similarly, specificity was above $80 \%$ for all items and above $90 \%$ for 19 of 21 items. More importantly, concerning the use of the MUPS in clinical practice, positive and negative predictive values of the single items were high for the majority of items.

There are, however, shortcomings of the present study to discuss. First, the baseline frequency of the nocturnal behaviors was low in our sample. In particular, none of the subjects showed signs of sleep-related eating disorders. Therefore, the database with respect to the sensitivity of the items has to be regarded as limited. On the other hand, specificity was based on a larger number of true negative cases and can be regarded as substantial for the MUPS. Second, the normal subjects did not constitute a representative sample of the general population and therefore generalizability of the results remains to be determined. Third, although overall data completeness was excellent, for one of the items more than $5 \%$ of the answers were missing. This item asked for periodic leg movements during sleep and can indeed be seen as problematic for several reasons. Early in the developmental stage of the questionnaire it became apparent that this question was very frequently misinterpreted. For this reason, we stressed both in the question and in the answer format that the leg movements occurred during sleep and could only be observed by other persons. Therefore, the relatively higher number of missing values most likely resulted from the fact that these subjects had no bed partner who could provide the relevant information. The second reason why this item is problematic refers to the general observability of periodic leg movements. Apart from the known night-to-night variability $[3,5,10]$, the vast majority of the sleep-disordered patients included in this study showed periodic leg movements during sleep to varying degrees. Although we have not formally assessed the specific correspondence, only about half of the persons included confirmed periodic leg movements suggesting that the questionnaire item underestimates the real prevalence. Despite these concerns, we have opted to include this item in the questionnaire for reasons of completeness, i.e. we wanted to assess all nocturnal movements listed in the ICSD-2 [1]; however, interpretation of this specific question must be taken with caution.

The MUPS was designed as a screening instrument to assess the occurrence and frequency of nocturnal behaviors and events. It does not claim to diagnose sleep-related disorders for several reasons. First, in the majority of sleep disorders some kind of functional consequence such as daytime fatigue or sleepiness needs to be evaluated, which is not part of the MUPS. Second, for some of the assessed behaviors such as night terrors, sleep walking or RBD a nocturnal polysomnography is recommended to assess in which sleep stage the nocturnal events occur or to differentiate the symptoms from 
other disorders such as epilepsy [6,22]. Our aim was to provide a screening questionnaire for use in sleep medicine; in particular, we wanted to enable the clinician to gain a quick overview on current or past nocturnal behaviors. As such, the questionnaire is optimized in terms of specificity based on the results of the validation study and we are reasonably confident that only a very low number of false positive answers - if at all - has to be expected. Regarding sensitivity, the questionnaire proved adequate in the current study but, given the low frequency of many of the nocturnal behaviors, this needs to be replicated in future larger studies. A low baseline frequency of positive cases, however, seems to be the rule rather than the exception in questionnaire validation studies (see Table 1). A notable exception is the recently developed RBD screening questionnaire [21] which was validated in 54 RBD patients, 133 normal subjects and 160 sleep-disordered patients (see Table 1). The authors of this questionnaire specifically sampled patients with RBD from a group of patients with Parkinson's disease where an increased prevalence of RBD is known $[7,19]$. We are currently in the process of evaluating the MUPS in patient samples enriched for the occurrence of parasomnias.

The MUPS proved feasible in three very different groups of subjects: healthy controls, sleep-disordered patients, and psychiatric patients. This distinguishes it from some of the other validated questionnaires which have only been assessed in groups of sleep-disordered patients, e.g. $[15,18]$. However, in our opinion it is the inclusion of a group of psychiatric patients that adds most to the potential clinical value of the MUPS. Although the underlying psychiatric disorder may be a factor regarding difficulty in answering the items cor- rectly, sensitivity and specificity were comparable across all three groups. A possible exception encountered in psychiatric patients occurred when day- and night-time symptoms were overlapping as in the case of hypnagogic hallucinations where an increased number of false positive answers were found.

In summary, we have presented the development and validation of the Munich Parasomnia Screening (MUPS). Our results suggest that the MUPS is a feasible instrument for clinical practice and research with adequate sensitivity and specificity that can be applied in different groups of subjects. Overall, the MUPS appears to be a valid instrument in the recognition of nocturnal behaviors and parasomnias.

\section{Appendix}

Download of questionnaires

English version

Instruction

http://www.charite.de/dgsm/dgsm/downloads/ fachinformationen

/frageboegen/MUPS_Instruction_English.pdf

Questionnaire http://www.charite.de/dgsm/dgsm/downloads/ fachinformationen /frageboegen/MUPS_English.pdf

Deutsche Version

Erläuterungen

http://www.charite.de/dgsm/dgsm/downloads/ fachinformationen

/frageboegen/MUPS_Erlaeuterungen_Deutsch. pdf

Fragebogen http://www.charite.de/dgsm/dgsm/downloads/ fachinformationen

/frageboegen/MUPS_Deutsch.pdf

Conflict of Interest: none.

\section{References}

1. American Academy of Sleep Medicine (2005) The international classification of sleep disorders: diagnostic and coding manual. $2^{\text {nd }}$ edition, American Academy of Sleep Medicine, Westchester, Illinois

2. Baldwin CM, Kapur VK, Holberg CJ, Rosen C, Nieto FJ (2004) Associations between gender and measures of daytime somnolence in the Sleep Heart Health Study. Sleep 27:305-311

3. Culpepper J, Shaffer JI, Badia P (1989) Within night variability in nocturnal myoclonus. Sleep Research 18:217

4. Douglass AB, Bornstein R, Nino-Murcia G, Keenan S, Miles L, Zarcone VP, Guilleminault C, Dement WC (1994) The Sleep Disorders Questionnaire I: creation and multivariate structure of SDQ. Sleep 17:160-167
5. Edinger JD, McCall WV, Marsh GR, Radtke, RA, Erwin CW, Lininger A (1992) Periodic limb movement variability in older DIMS patients across consecutive nights of home monitoring. Sleep 15:156-161

6. Eisensehr I, v Lindeiner $H$, Jäger $M$, Noachtar S (2001) REM sleep behavior disorder in sleep-disordered patients with versus without Parkinson's disease: is there a need for polysomnography? J Neurol Sci 186:7-11

7. Gagnon JF, Bedard MA, Fantini ML, Petit D, Panisset M, Rompre S, Carrier J, Montplaisir J (2002) REM sleep behavior disorder and REM sleep without atonia in Parkinson's disease. Neurology 59:585-589

8. Guilleminault C, Leger D, Philip P, Ohayon MM (1998) Nocturnal wandering and violence: review of a sleep clinic population. J Forensic Sci 43:158-163
9. Gulich M, Heil P, Zeitler HP (1998) Epidemiology and determinants of nocturnal calf cramps. Eur J Gen Pract 4: 109-113

10. Hornyak M, Kopasz M, Feige B, Riemann D, Voderholzer U (2005) Variability of periodic leg movements in various sleep disorders: implications for clinical and pathophysiologic studies. Sleep 28:331-335

11. Hublin C, Kaprio J (2003) Genetic aspects and genetic epidemiology of parasomnias. Sleep Med Rev 7:413-421

12. Lavigne GJ, Montplaisir JY (1994) Restless legs syndrome and sleep bruxism: prevalence and association among $\mathrm{Ca}$ nadians. Sleep 17:739-743

13. Loong TW (2003) Understanding sensitivity and specificity with the right side of the brain. Br Med J 327:716-719 
14. Ohayon MM, Guilleminault C, Priest RG (1999) Night terrors, sleepwalking, and confusional arousals in the general population: their frequency and relationship to other sleep and mental disorders. J Clin Psychiatry 60:268-276

15. Ohayon MM, Guilleminault C, Zulley J, Palombini L, Raab H (1999) Validation of the Sleep-Eval System against clinical assessments of sleep disorders and polysomnographic data. Sleep 22:925930

16. Ohayon MM, Li KK, Guilleminault C (2001) Risk factors for sleep bruxism in the general population. Chest 119:5361

17. Ohayon MM, Priest RG, Guilleminault C, Caulet M (1996) Nightmares: their relationship with mental disorders and sleep disorders. Eur Neuropsychopharmacol 6:136-137
18. Roth T, Zammit G, Kushida C, Doghramji $\mathrm{K}$, Mathias SD, Wong JM, Buysse DJ (2002) A new questionnaire to detect sleep disorders. Sleep Med 3:99-108

19. Scaglione C, Vignatelli L, Plazzi G, Marchese R, Negrotti A, Rizzo G, Lopane G, Bassein L, Maestri M, Bernardini S, Martinelli P, Abbruzzese G, Calzetti S, Bonuccelii U, Provini F, Coccagna G (2005) REM sleep behaviour disorder in Parkinson's disease: a questionnairebased study. Neurol Sci 25: 316-321

20. Spoormaker VI, Verbeek I, van den Bout J, Klip EC (2005) Initial validation of the SLEEP-50 questionnaire. Behav Sleep Med 3:227-246

21. Stiasny-Kolster K, Mayer G, Schäfer S, Möller JC, Heinzel-Gutenbrunner M, Oertel WH (2007) The REM sleep behavior disorder screening questionnaire - A new diagnostic instrument. Mov Disord: 22:2386-2393
22. Tinuper P, Provini F, Bisulli F, Vignatelli L, Plazzi G, Vetrugno R, Montagna $\mathrm{P}$, Lugaresi E (2007) Movement disorders in sleep: guidelines for differentiating epileptic from non-epileptic motor phenomena arising from sleep. Sleep Med Rev 11:255-267

23. Vander Wal JS, Waller SM, Klurfeld D, McBurney MI, Dhurandhar NV (2005) Night eating syndrome: evaluation of two screening instruments. Eat Behav 6: 63-73

24. Winkelman JW, Herzog DB, Fava M (1999) The prevalence of sleep-related eating disorder in psychiatric and nonpsychiatric populations. Psychol Med 29:1461-1466

\section{IMMER EINE FRISCHE BRISE mit unseren Atemtherapiesystemen}

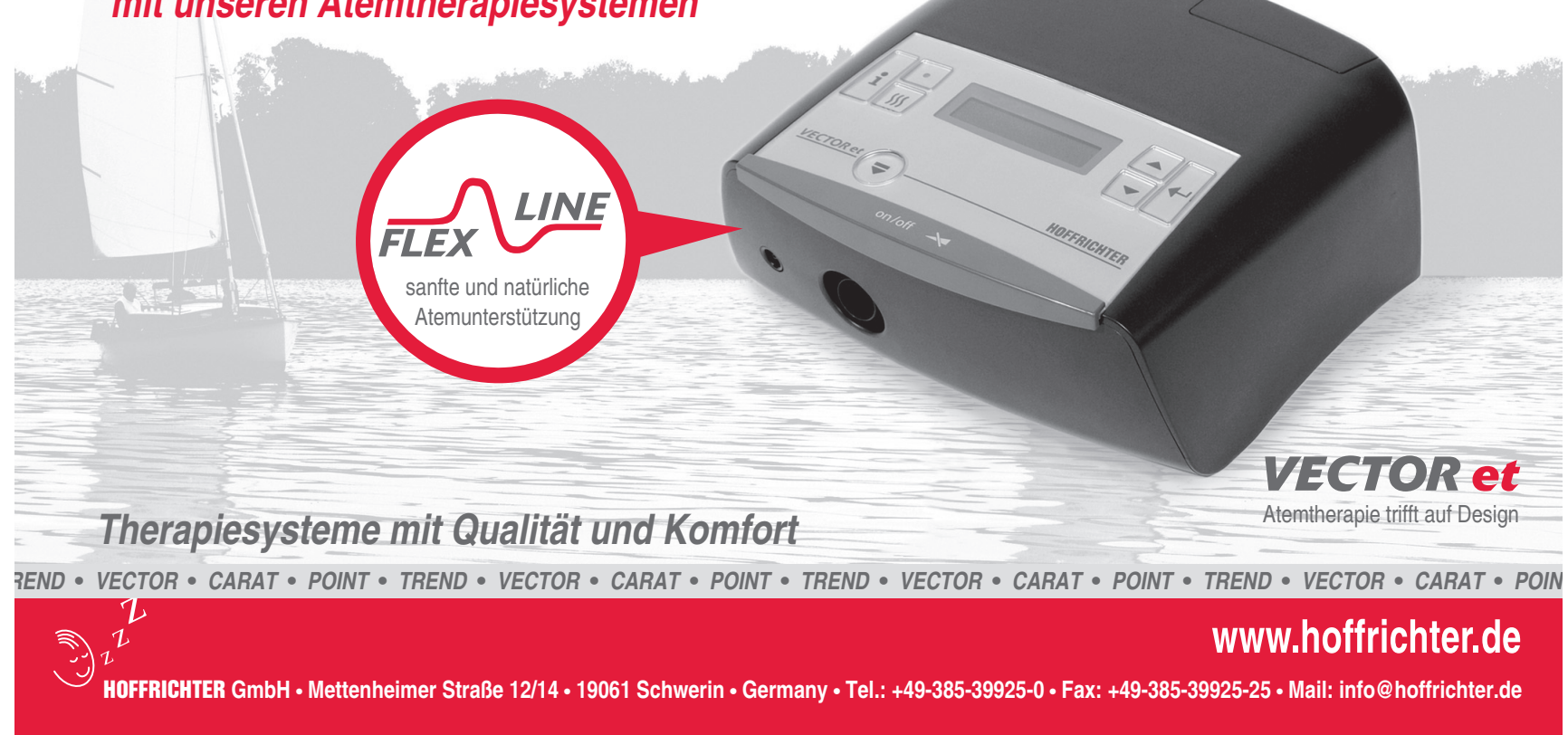

